\title{
Crows learn not to respond under response-independent reinforcement
}

\author{
ROBERT W. POWELL and WILLIAM A. KELLY \\ University of South Florida, Tampa, Florida 33620
}

\begin{abstract}
Seven fish crows were trained to respond under either fixed-or variable-interval schedules. Subsequently, the response dependency was systematically eliminated and then reinstated. The distribution of reinforcers in time was the same under the response-independent schedules as had prevailed under the response-dependent schedules. Responding was successfully maintained for all birds when the response dependency was in effect, but it eventually ceased under the response-independent procedure. Responding resumed when the response dependency was reinstated. Terminal patterns of responding under each of the interval schedules were similar to those displayed by pigeons. However, compared to pigeons, fish crows showed substantially less responding under response-independent procedures. An explanation of this result is offered that stresses differences between crows and pigeons in their natural feeding patterns in relation to the type of response (pecking) required to obtain food in the experiment.
\end{abstract}

A number of investigators have studied the effects of delivering response-independent reinforcement to animals following training on response-dependent procedures (Alleman \& Zeiler, 1974; Appel \& Hiss, 1962; Edwards, Peek, \& Wolfe, 1970; Edwards, West, \& Jackson, 1968; Lattal, 1972, 1974; Lowe \& Harzen, 1977; Zeiler, 1968, 1976). A response-independent procedure involves the presentation of food following either fixed or variable time periods irrespective of behavior. These schedules are denoted as fixed time (FT) and variable time (VT) to distinguish them from their response-dependent counterparts, fixed interval (FI) and variable interval (VI). The usual finding with pigeons when the response dependency is removed is that the rate of responding decreases relative to the responsedependent schedule, but remains well above zero (Edwards et al., 1968; Herrnstein, 1966).

Recent evidence suggests that sustained responding under response-independent procedures may be accounted for in several ways. Brown and Jenkins (1968) showed that pigeons develop keypecking when no response contingency exists (autoshaping). The mere presentation of a briefly illuminated response key followed by the presentation of food engenders keypecking. Still others (Killeen, 1975; Staddon \& Simmelhag, 1971) have reported that the delivery of food to untrained pigeons on a FT schedule results in frequent pecking. In addition, responding increases as the time of food presentation approaches. This evidence suggests that pecking in pigeons is not an arbitrary

This experiment is based on a thesis submitted by the second author to the Department of Psychology, University of South Florida, in partial fulfillment of the requirements for the MA degree. A version of this paper was presented at the annual meeting of the Psychonomic Society, Washington, D. C., November 1977. Reprints may be obtained from Robert W. Powell, Department of Psychology, University of South Florida, Tampa, Florida 33620. operant, but may occur because food elicits pecking.

In the present experiment, fish crows were studied under FT and VT schedules following extensive training under FI and VI schedules, respectively. Fish crows were chosen for several reasons. First, they can be trained to keypeck for food but show little, if any, responding under autoshaping procedures (Powell, Kelly, \& Santisteban, 1975). Second, we have found that common crows develop response patterns quite similar to pigeons under fixed-ratio (FR), variableratio (VR), and VI schedules, but show substantially different patterns under FI schedules (Powell, 1972), where they often make only a small number of responses during the interreinforcement interval. In addition, common crows respond much more successfully under differential reinforcement of low rate (DRL) schedules than do pigeons (Powell, 1974). Also, we have recently reported that common crows show negative induction when switched from a multiple (mult) VI-VI schedule to a mult VI-VT schedule (Powell, Kelly, \& Palm, 1978). Pige ons show a decrease in VT responding but no change in VI responding under these procedures (Halliday \& Boakes, 1971; Marcucella, 1976). Thus, crows may have greater capacity to inhibit keypecking than pigeons, and their behavior may also be more sensitive to the influence of temporal cues.

The habitat preference of the common crow can best be described as pastures with adjoining woods, whereas fish crows thrive in a littoral habitat. While both species are omnivorous, the fish crow is less dependent on agricultural products and fares well on native vegetation (Johnston, 1961). Finally, fish crows are members of a genus of birds that is thought by some ornithologists (Thomson, 1964) to represent the most advanced stage of avian evolution.

The purpose of the present experiment was twofold: (1) to study the generality of the data obtained from the fish crow under FI and VI schedules in relation to other 
species, particularly common crows and pigeons, and (2) to study response-independent schedules in an avian species in which pecking is apparently not elicited by the presentation of food.

\section{METHOD}

\section{Subjects}

Seven adult fish crows (Corvus ossifraguz), which had been trapped in the field as adults, were used. The crows had been maintained in captivity for approximately 2 years prior to the experiment. They all had prior experience in an autoshaping experiment (Powell et al., 1975), but little responding developed under this procedure. The crows were maintained at approximately $80 \%$ of their free-feeding weights (FFWs) throughout the experiment. The FFWs ranged from 256 to $350 \mathrm{~g}$. The crows were housed in individual cages with water and grit freely available.

\section{Apparatus}

Two Lehigh Valley Electronics test chambers were used, including a standard pigeon test chamber (Model 1519C) and a large bird test chamber (Model 132-06). The latter chamber was modified with emory board partitions so that its interior dimensions corresponded to those of the pigeon test chamber $(38.8 \times 38.5 \times 33.0 \mathrm{~cm}$, height $\mathrm{x}$ width $\times$ length). Both chambers had more than one response key, but only the right-hand key was used in each case, with the other key covered. White noise at approximately $90 \mathrm{~dB}$ was presented within the test chamber to mask extraneous sounds. Top Choice, a processed dog food, served as the reinforcer. Data were recorded by digital counters and Gerbrands cumulative recorders.

\section{Procedure}

Preliminary training. After being reduced to $80 \%$ of their FFWs, the birds were magazine trained. The crows were then shaped to peck the key through the method of successive approximation. Once keypecking was acquired, the birds received brief training under a continuous reinforcement (CRF) schedule. Reinforcement time was $3.0 \mathrm{sec}$ for all crows except C48, for whom it was $2.0 \mathrm{sec}$. Experimental sessions were conducted daily throughout the experiment.

Phase 1: Response-dependent procedure. Following preliminary training, all birds were studied under VI or FI schedules: (1) Crows 15, 25, and 90 were studied under VI schedules of 20 , 40,80 , and $120 \mathrm{sec}$. Each schedule remained in effect for a minimum of 10 sessions, and training continued until perform- ance was stable. Throughout the experiment, stability was defined as a response rate remaining within $\pm 10 \%$ of the mean rate over three consecutive sessions. (2) Crows $1,48,91$, and 92 were studied under FI schedules of $20,40,80$, and $120 \mathrm{sec}$ with the same conditions in effect as for the VI schedules.

Phase 2: Response-independent procedure. When responding stabilized for each crow under either VI or FI $120 \mathrm{sec}$, the response dependency was removed. Reinforcement was then presented on VT or FT schedules for the VI and FI birds, respectively. The stability criterion remained the same, and an additional criterion was added that required the schedule value to change whenever 10 or fewer responses occurred in each of three consecutive sessions. When performance stabilized under either FT or VT $120 \mathrm{sec}$, the schedule requirement increased to $180 \mathrm{sec}$ and $240 \mathrm{sec}$, and then decreased to $180 \mathrm{sec}$ and $120 \mathrm{sec}$ for all birds. Crows 1,43 , and 90 were then exposed to schedule values of 60 and $15 \mathrm{sec}$, while the other four crows went from 120 to $15 \mathrm{sec}$. The rationale for the large schedule change was based upon the fact that the crows were responding at essentially the zero level under the $120-\mathrm{sec}$ schedule. We reasoned that a substantial increase in the frequency of reinforcer presentations might engender responding.

Phase 3: Response-dependent procedure. Finally, the response dependency was reinstated. The four crows that had been exposed to fixed schedules were studied under FI schedules of 60,120 , and $240 \mathrm{sec}$. The three crows with variable schedule training were studied under VI schedules of 60,120 , and $240 \mathrm{sec}$. The same performance criteria as noted earlier were observed.

\section{RESULTS}

The principal dependent measure studied under all conditions was rate of response. We were also interested in postreinforcement pausing under the fixed schedules (FI, FT) and response patterns under all conditions, as shown in cumulative response records. Mean response rates were determined by dividing the number of responses by the total session time minus the reinforcement time. The terminal response rates for each crow at all schedule values are shown in Figure 1. The most notable effect was that all crows responded at lower rates when reinforcement was presented independently of responding. Only Crows 1 and 48 showed appreciable responding at any time under the response-independent

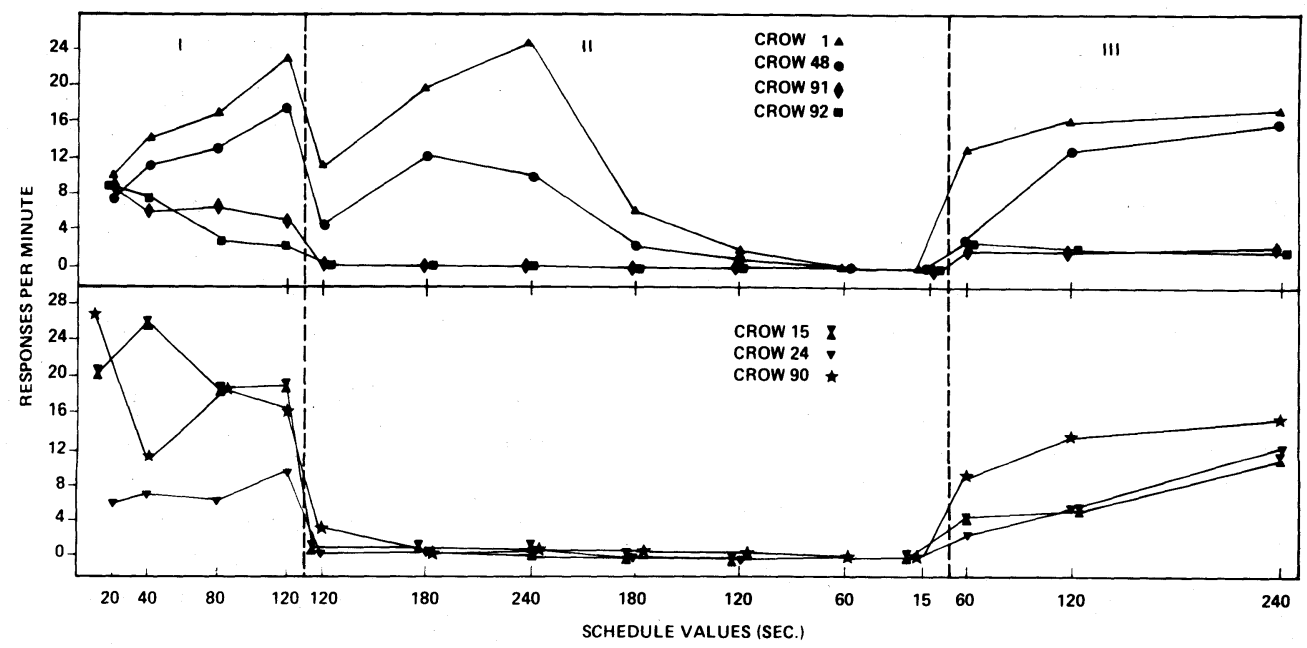

Figure 1. Mean response rates over the final five sessions at each schedule value. The top graph reports the data for the four fixed schedule birds. The data for the three variable schedule birds are presented in the bottom graph. 
procedure, and these birds, like the other five crows, eventually ceased responding under this procedure. Figure 1 shows further that responding resumed when the response dependency was reinstated, and that rates eventually recovered to approximately $70 \%$ of the level initially attained under VI and FI schedules.

While there appeared to be a positive correlation between rate of responding under the FI schedules and rate of responding under the FT schedules, no similar effect was observed for the variable schedule birds. During Phase 1 , Crows 15 and 90 had response rates under VI that were similar to the rates for Crows 1 and 48 under FI. However, when the response contingency was removed, the variable schedule birds showed rapid and substantial decreases in responding. Further inspection of Figure 1 reveals that there was no consistent relationship between response rate and reinforcement frequency under the response-dependent schedules. Under the FI schedules, Crows 1 and 48 generally showed increases in responding as the frequency of reinforcement decreased, while Crows 91 and 92 showed the opposite trend. The crows studied under VI schedules showed inconsistent relationships between response rate and reinforcement frequency during Phase 1 , and then a gradual increase in rate as reinforcement frequency decreased in Phase 3.

In general, then, the birds fell into three distinct groups relative to their performance during the entire experiment. Under the fixed schedules, Crows 1 and 49 had consistently higher response rates then Crows 91 and 92, except for the final FT values. The performance for the three crows studied under variable schedules was similar. Figure 2 presents the complete performance for one crow selected from each of these subgroups, over the entire experiment. In each case it can be seen that the crows were sensitive to the change from responsedependent to response-independent reinforcement. Responding showed a marked decrease for each bird when the response dependency was removed, and there was a notable increase when the dependency was reinstated. The latter effect occurred even though responding was at a near-zero level for all crows during the final response-independent sessions.

The postreinforcement pause under the fixed schedules was measured from the end of the reinforcer presentation to the first response that occurred during the interval. Figure 3 shows that there was a very consistent and direct relationship between the length of the FI schedule and the mean postreinforcement pause duration.

\section{DISCUSSION}

The most noteworthy result was the cessation of responding by all of the crows under response-independent reinforcement. In fact, five of the seven birds showed a rapid decrease in responding when the response dependency was removed. It is also important to note that responding resumed immediately in all birds when the response dependency was reinstated. Thus, response-independent reinforcement does not maintain

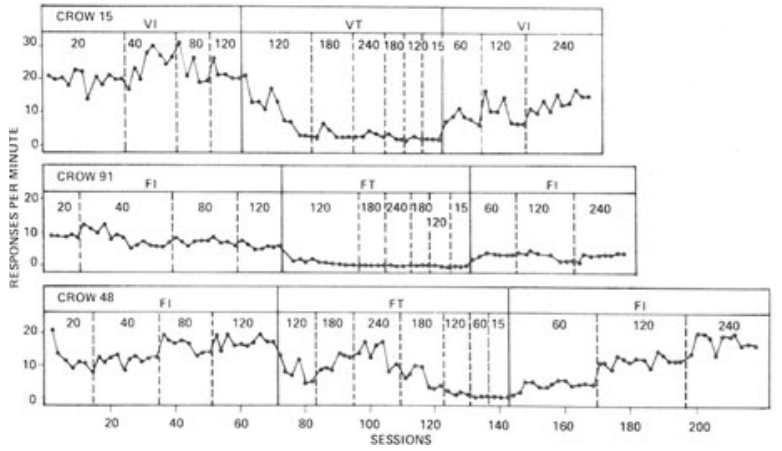

Figure 2. Rate of responding for three of the crows over the entire experiment. Data points represent means over two sessions.

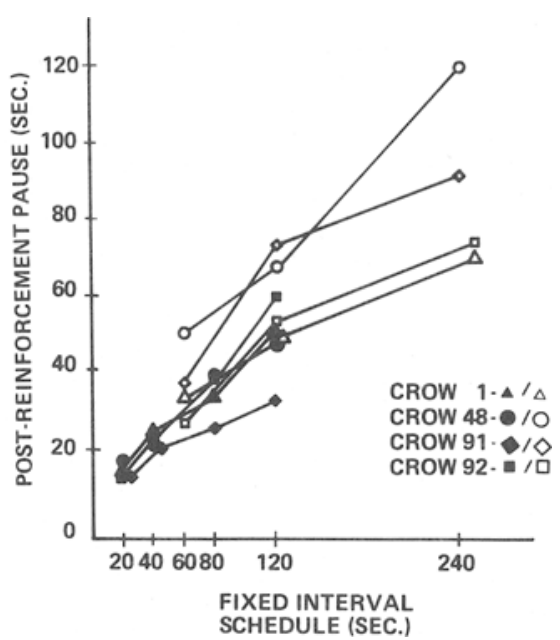

Figure 3. Postreinforcement pause (PRP) duration for each of the four crows studied under FI schedules, Phase 1 (closed circles) and Phase 3 (open circles). Each data point is based on the first 10 pauses during each of the last five sessions at each schedule requirement.

responding in crows for extended periods, but often does so quite effectively in pigeons (Appel \& Hiss, 1962; Staddon \& Simmelhag, 1971). The crows did show response patterns similar to pigeons under the response-independent schedules as long as consistent responding was main tained.

The most pertinent study with which to compare the present findings would appear to be that of Lowe and Harzem (1977), who systematically analyzed the performance of domesticated rats and pigeons under FI and FT schedules. They found that on FT schedules, rats' responding decreased greatly or ceased, whereas pigeons continued to respond over extended periods, especially on low schedule values. Thus, the results obtained here with crows are more similar to those of rats than those of pigeons. This finding is not unique in that the DRL performance of crows was quite dissimilar to pigeons, but comparable, if not superior to, DRL performance in rats (Laties, Weiss, \& Weiss, 1969; Powell, 1974).

Lowe and Harzem (1977) favor an explanation of their findings in terms of differences between keypecking in pigeons and leverpressing in rats, as these responses are elicited by the presentation of food. We have previously offered a similar explanation in attempting to account for differences in conditioning effects between crows and pigeons (Powell, 1974; Powell et al., 1975). That is, pecking is elicited by the presentation of food in pigeons, but not in crows. This appears to relate to the fact that crows are omnivorous and possess a varied feeding 
pattern, whereas pigeons are almost exclusively grainiverous and display stereotyped feeding behavior. It seems noteworthy that both crows and the forebearers of domesticated rats are generalists in the ecological sense. Pigeons, on the other hand, are much more specialized. Thus, the similarities in conditioning effects uncovered so far appear to reside along the lines of ecological, rather than anatomical, similarity. This finding appears to be consistent with the view that learning mechanisms and their attendant processes are products of the evolutionary history of a particular species. Consequently, since species differ in their evolutionary histories, different learning mechanisms should have evolved, and these mechanisms should be consonant with the demands imposed by each species' ecological niche (Seligman, 1970).

Pigeons show a direct relationship between response rate and reinforcement rate under interval schedules (Catania \& Reynolds, 1968), but no such relationship was observed here. In fact, an overview of the data for the crows studied here and those studied earlier under interval schedules (Powell, 1972) shows a relatively constant response rate over a range of FI and VI values. This difference can be plausibly explained also on the basis of food-elicited pecks that occur in pigeons but not in crows. Consequently, as the interval decreases and rate of reinforcement increases, there is an increase in the number of elicited pecks within a given time period for pigeons. This, in turn, produces a higher overall response rate.

The present findings question the generality of results obtained from pigeons under response-independent reinforcement. It may well be that these results extend only to other avian species that, like pigeons, exhibit repeated pecking in the course of foraging behavior. The species that are most similar appear to be chickens, quail, and doves. When one considers the vast array of feeding ecologies that have evolved among avian forms, ranging from the carnivorous birds of prey to the nectarfeeding hummingbird, it is obvious that pecking is not a prototype for feeding behavior in birds, even though claims to the contrary have sometimes been made (Mackintosh, 1974, p. 136). Nor can any other feeding pattern be taken as a prototype. Consequently, the pecking response of the pigeon and some of the conditioning phenomena that are attendant with it are probably representative of only a narrow range of the total avian spectrum. It appears that we need to extend our study of conditioning phenomena so that it encompasses a much broader range of consummatory responses.

\section{REFERENCES}

Alleman, H. D., \& Zeiler, M. D. Patterning with fixed-time schedules of response independent reinforcement. Journal of the Experimental Analysis of Behavior, 1974, 22, 135-141.

Appel, J. B., \& Hiss, R. H. The discrimination of contingent from noncontingent reinforcement. Journal of Comparative and Physiological Psychology, 1962, 55, 37-39.

Brown, P. L., \& Jenkins, H. M. Autoshaping of the pigeons keypeck. Journal of the Experimental Analysis of Behavior, 1968, 14, 1-8.

Catania, A. C., \& Reynolds, G. S. A quantitative analysis of the responding maintained by interval schedules of reinforcement. Journal of the Experimental Analysis of Behavior, 1968, 11, 327-383.

Edwards, D. D., PeEK, R., \& Wolfe, R. Independently delivered food decelerates fixed-ratio rates. Journal of the Experi- mental Analysis of Behavior, 1970, 14, 301-307.

Edwards, D. D., West, J. R., \& Jackson, V. The role of contingencies in the control of behavior. Psychonomic Science, $1968,10,39-40$.

Halliday, M. S., \& Boakes, R. A. Behavioral contrast and response-independent reinforcement. Journal of the Experimental Analysis of Behavior, 1971, 16, 429-434.

HerRnste in, R. J. Superstition: A corollary of the principles of operant conditioning. In W. K. Honig (Ed.), Operant behavior: Areas of research and application. New York: AppletonCentury-Crofts, 1966.

Johnston, D. W. The biosystematics of the American crows. Seattle: University of Washington Press, 1961.

Killeen, P. On the temporal control of behavior. Psychological Review, 1975, 82, 89-116.

Laties, V. G., Weiss, B., \& Weiss, A. B. Further observations on overt "mediating" behavior and the discrimination of time. Journal of the Experimental Analysis of Behavior, 1969, 12, 43-57.

LAtTAL, K. A. Response-reinforcer independence and conventional extinction after fixed-interval and variable interval schedules. Journal of the Experimental Analysis of Behavior, 1972, $18,133-140$.

Lattal, K. A. Combinations of response-reinforcer dependence and independence. Journal of the Experimental Analysis of Behavior, 1974, 22, 257-364.

Lowe, C. F., \& Harzem, P. Species differences in temporal control of behavior. Journal of the Experimental Analysis of Behavior, 1977, 38, 189-201.

Mackintosh, N. J. The psychology of animal learning. London: Academic Press, 1974.

Marcucella, H. Signaled reinforcement and multiple schedules. Journal of the Experimental Analysis of Behavior, 1976, 26, 199-206.

Powell, R. W. Responding under basic schedules of reinforcement in the crow. Journal of Comparative and Physiological Psychology, 1972, 79, 156-164.

Powell, R. W. Comparison of differential reinforcement of low rates (DRL) performance in pigeons (Columbia livia) and crows (Corvus brachyrhynchos). Journal of Comparative and Physiological Psychology, 1974, 86, 736-746.

Powell, R. W., Kelly, W., \& PAlm, L. Behavioral contrast and induction in the crow. Behavioral Biology, 1978, 24, 49-56.

Powell, R. W., Kelly, W., \& Santisteban, D. Response independent reinforcement in the crow. Failure to obtain autoshaping or positive automaintenance. Bulletin of the Psychonomic Society, 1975, 6, 513-516.

Seligman, M. E. On the generality of laws of learning. Psychological Review, 1970, 77, 406-418.

Staddon, J. E., \& Simmelhag, V. L. The "superstition" experiment: A reexamination of its implications for the principles of adaptive behavior. Psychological Review, 1971, 78, 3043.

Thomson, A. L. (Ed.). A new dictionary of birds. New York: McGraw-Hill, 1964.

ZEILER, M. D. Fixed and variable schedules of reponse-independent reinforcement. Journal of the Experimental Analysis of Behavior, 1968, 11, 405-414.

ZEILER, M. D. Conjunctive schedules of response-dependent and response-independent reinforcement. Journal of the Experimental Analysis of Behavior, 1976, 26, 505-521.

(Received for publication March 26, 1979.) 